\title{
One Pot Synthesis and Spectral Analysis of Ag Doped Polyvinyl Pyrrolidone Encapsulated Zinc Oxide Nano Composites and its Antibacterial Efficacy
}

\author{
Saravana Vadivu Arunachalam, Arunpandian. M
}

\begin{abstract}
A facile wet chemical method is used for the preparation of the transition metal doped semiconducting materials. To prepare pure PVP encapsulated $\mathrm{ZnO}$ nano particles by taking $1 \mathrm{~g}$ $P V P$ which was dissolved in $50 \mathrm{ml}$ of ethanol and the solution is stirred for 2 hours at room temperature. After the stirring process zinc nitrate of $(0.5,1.0,1.5) g$ was added and to this solution add $0.1 \mathrm{~g}$ of silver nitrate and stirr vigarously. The resultant product is kept aside for ten day, then dried under vacuuo and annealed.The synthesized nano material was preserved in an airtight container and it is subjected for various spectral investigation tools like $X$ -Ray Diffraction analysis, High Resolution Scanning Electron microscope Analysis, Photoluminescence studies, Ultra Violet Absorption and Fourier Transform Infrared Spectroscopic studies. The XRD results reveal that the synthesized samples are in highly crystalline in state and also show that the sample does not contain any metal peak which shows that the synthesized samples are in highly pure phase. The HR SEM result shows that the materials are in Nano phase. The $U V$ visible absorption spectroscopic study shows strong absorption peaks of $\mathrm{ZnO}$ around $295 \mathrm{~nm}$ and $\mathrm{Ag}$ doped $\mathrm{ZnO}$ around $280 \mathrm{~nm}$ which is caused by the band edge transition of the synthesized semiconductor. The FTIR studies are also shows characteristic peaks for PVP, ZnO, Ag doped $\mathrm{ZnO}$ nanocomposites. The $\mathrm{ZnO}$ nano material behaves as a potential antimicrobial agent but the silver doped $\mathrm{ZnO}$ shows a lesser activity while comparing with the standard drug (Streptomycin).
\end{abstract}

Keywords: PVP encapsulated ZnO, One pot synthesis, Nano phase, Streptomycin, Biological study

\section{INTRODUCTION}

Recently, major interest has been devoted to the transition metal oxides doped with the different substrates [1]. These materials are good candidates for applications in semiconductors, photocatalysis, sensors, antimicrobial agents and displays [2-8]. Silver and silver-based compounds are well-investigated antimicrobial agents being biocompatible and non-toxic to human cells at concentrations effective against microorganisms when in the form of non-agglomerated and well dispersed nanoparticles [9-12]. In this communication, we are reporting versatile approach to synthesize materials/products that are in powdery form and are veryeffective as antibacterial agents. We have conducted

Revised Manuscript Received on December 05, 2019

* Correspondence Author

S. Arunachalam*, Nanomaterials Laboratory, Department of Chemistry, International Research Centre, Kalasalingam Academy of Research and Education (Deemed to be University), Krishnankoil - 626126, India. Email: drarunachalam.s@gmail.com

M. Arunpandian, Nanomaterials Laboratory, Department of Chemistry, International Research Centre, Kalasalingam Academy of Research and Education (Deemed to be University), Krishnankoil - 626126, India. Email: arunpandiantt126@gmail.com investigations on the efficacy of silver-doped product and non-silver doped product. The un-embedded product was also prepared and subjected to the same treatment to serve as reference. A project on further innovative industrial applications of these products is in progress.

\section{EXPERIMENTAL DETAILS}

Materials and Methods

All the reagents used were analytical reagent grade. Solvents were purified and dried according to the standard procedures.

All the reactions were carried out under anhydrous conditions. Zinc nitrate, Silver nitrate, Polyvinyl pyrolidone (PVP), ethanol was purchased from Sigma and was used without further purification. The analysis of carbon, hydrogen, nitrogen and sulphur were performed in Vario EL III CHNS analyzer at Cochin University, Kerala, India. IR spectra were recorded as $\mathrm{KBr}$ pellets in the $4000-400 \mathrm{~cm}-1$ region using a Shimadzu FT-IR 8000 spectro-photometer. Electronic spectra were recorded in dichloromethane Melting points were recorded on a Veego VMP-DS melting point apparatus and are uncorrected.

To prepare pure PVP encapsulated $\mathrm{ZnO}$ nano particles by taking $1 \mathrm{~g}$ polyvinyl pyrrolidone which was dissolved in 50 $\mathrm{ml}$ of ethanol and the solution is stirred for 2 hours at room temperature. After the stirring process zinc nitrate of $(0.5$, $1.0,1.5) \mathrm{g}$ was added to the solution and stirred which was completely dissolved into the solution.

The solution was poured into a Petri dish and kept in a dark room for ten days. Then it can be kept into a vacuum desiccator and then the particles are collected and grained and preserved in an air tight container. The flow chart for the preparation of PVP encapsulated $\mathrm{ZnO}$ nano particles is given below, 


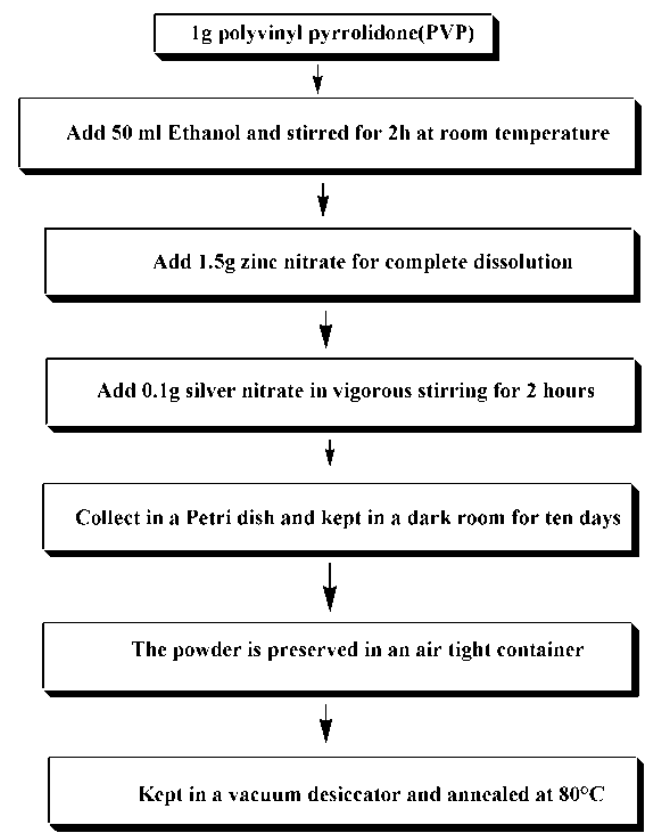

\section{Antimicrobial Activity}

A smear was prepared on a glass slide using a sterile wire loop and allowed to dry. Fixed the smear by passing the slide rapidly over the flame. Stained it for 1 minute with crystal violet solution and washed it in tap water. Applied the gram's iodine solution and washed it in tap water after 1 minute. Decolorized with alcohol by adding dropwise on the titled slide. Appile the counter strain for 1 minute, washed and air-dried.

Melted the agar in the tubes while sterilizing, cooled it and keep it at 450 C. Poured about $20 \mathrm{ml}$ of the agar medium into each of the petridishes. Allowed them to cool and labeled the petridishs. Added the required gut sample from the rearing medium into the sterile water in test tubes, shaken the test tubes and allowed to settle. Using a sterilize $1 \mathrm{ml}$ pipette added $1 \mathrm{ml}$ sample each into the plates and spreaded the plate by tilting it back and forth or using a sterile ' $\mathrm{L}$ ' rod. Left a plate as control. Inverted all the plates and incubated them at $300 \mathrm{C}$ is an incubator for 2 days, observed different types of colonies.

\section{RESULTS AND DISCUSSION}

\section{Ray Diffraction Structural Analysis:}

The XRD pattern of PVP ( $1 \mathrm{gm})$ encapsulated $\mathrm{ZnO}(0.5$ $1.5 \mathrm{gm})$ nanoparticles prepared at room temperature is represented in FIGURE1.a (Tables 1). The sharp diffraction peaks of miller planes (100), (101), (102), (103) indicate the crystalline $\mathrm{ZnO}$ hexagonal wurtzite structure, which are agreed well with the standard JCPDS card (21-1272). Intensity of the diffraction peaks enhance with the $\mathrm{ZnO}$ concentration in the growth medium.

Further, upon increasing concentration, it shows feeble shift towards the lower angle in their positions. The average particle sizes calculated from the analysis using 'Debye Scherer' formula is found to be $15 \mathrm{~nm}$. As the $\mathrm{Zn}$ precursor ratio is increased to $1.0 \mathrm{gm}$, the crystallinity of the materials is also increased. Further raise in the concentration results with formation of multiple faceted orientations [13].

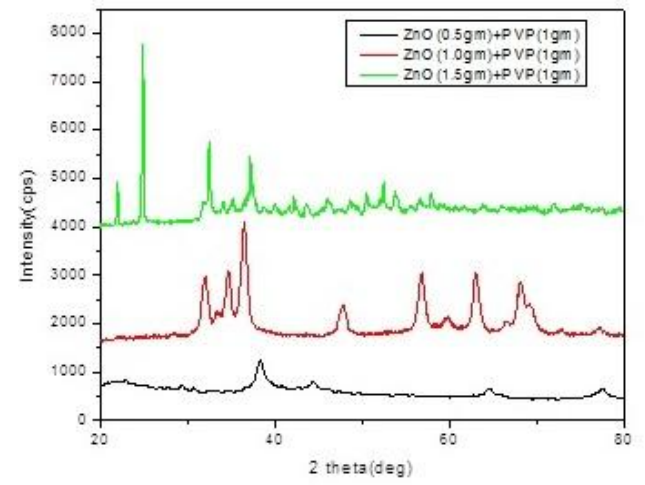

Figure 1.a. XRD pattern of $\mathrm{ZnO}$ nanoparticles

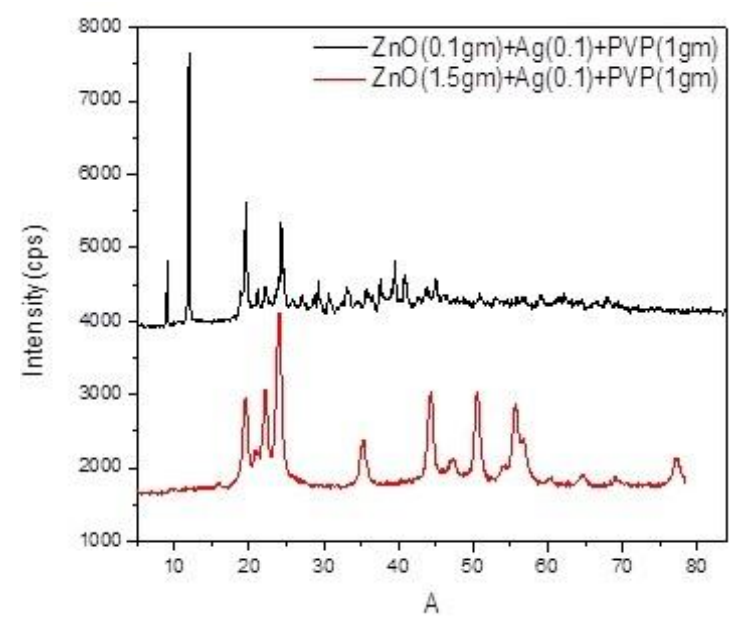

Figure 1.b. XRD pattern of Silver doped ZnO Nanocomposites

Figure1.b shows the XRD spectra of Agdoped $\mathrm{ZnO}$ encapsulated with PVP nano composites prepared for low concentration of $\mathrm{ZnO}$ nanoparticles are shown in the Figure 5.1(b) which exhibit the presence of hexagonal structured $\mathrm{ZnO}$ doped with $\mathrm{Ag}$ in the PVP matrix. The figure also shows the prominent peaks at $2 \theta$ angles namely $35.89^{\circ}, 37.62^{\circ}$, $40.82^{\circ}$ and $44.93^{\circ}$ and are related to the plane values (004), (101), (102) and (103) respectively. The presence of a less intense peak at $35.89^{\circ}$ is correlated to the miller plane (004) doped state of low concentrated $\mathrm{ZnO}$ present in the PVP matrix. The other peaks are matched with the standard data JCPDS card number (89-0510). The average crystallite size of the doping material is calculated ranged between 15 and 30 $\mathrm{nm}$.

\section{UV VISIBLE SPECTROSCOPY:}

The absorption spectra of the $\mathrm{ZnO}$ nanostructures dispersed in PVP matrices spread in ethanol solution is shown in figure 2.a. and the results given in the table 2. The band position corresponds to $\mathrm{ZnO}$ nanoparticles are blue shifted from their characteristics absorption region due to the size reduction and controlled by PVP materials. The blue shift in the absorption edges is attributed to the quantum confinement of the $\mathrm{ZnO}$ nanostructures. Intensity of the absorption edges increases with increased with the $\mathrm{Zn}$ concentration and it infers the more formation of $\mathrm{ZnO}$. Further, it supports the XRD results. 


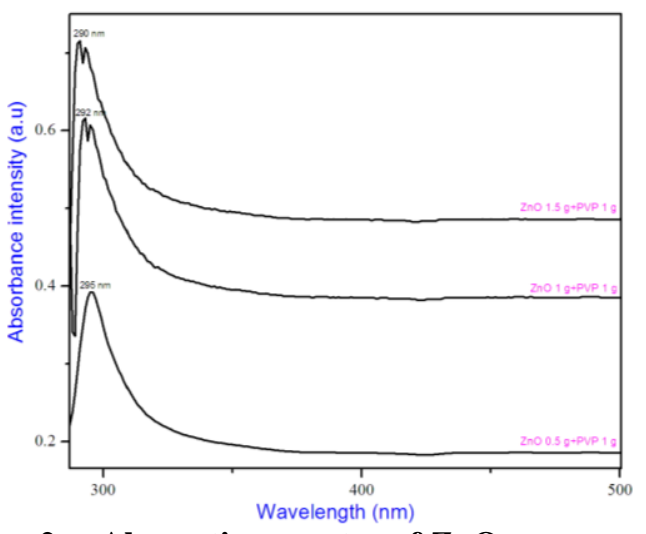

Figure 2.a. Absorption spectra of $\mathrm{ZnO}$ nano particle with PVP (1.0 gm)

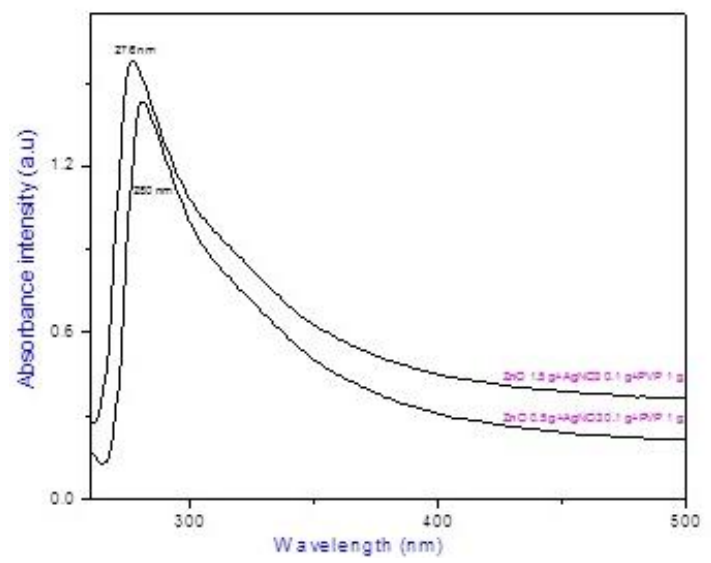

Figure 2.b.UV-Visible spectrum of Silver doped ZnO nanocomposites

The optical properties of PVP encapsulated $\mathrm{ZnO}$ nanoparticles are showed in the figure 2.b. and the results given in the table 2. The sharp absorption band at $295 \mathrm{~nm}$ is attributed to the monodispersed state of the prepared nanosystems. Band gap energy was calculated from the spectrum which ensemble the increased energy gap which is also further resembled the reduced particle size of the nanoparticles. The sharpness of the absorption edge denotes the less defect particles in the PVP matrices. The PVP encapsulated $\mathrm{ZnO}$ nanoparticles (0.5 to $1.5 \mathrm{gm})$ shows decrease in absorption intensity, due to the increase of $\mathrm{ZnO}$ nanoparticles in the PVP matrix. The band gap energy was calculated for high concentration $\mathrm{ZnO}$ which shows decreased state due to the increase the concentration of $\mathrm{ZnO}$ nanoparticles in the PVP matrix.

The optical properties of PVP encapsulated Silver doped $\mathrm{ZnO}$ nanocomposites showed that the absorption peak at 280 $\mathrm{nm}$. The $0.1 \mathrm{~g}$ Agparticles doped with $0.5 \mathrm{gm}, 1.5 \mathrm{gm}$ of $\mathrm{ZnO}$ in the concentration of $1 \mathrm{gm}$ PVP matrix. The absorption peak position decreases due to the doping of Agparticle with $\mathrm{ZnO}$ nanoparticle in the PVP matrix. The bandgap energy was calculated and it was slightly increasing than the $\mathrm{ZnO}$ nanoparticles [14].

\section{PHOTOLUMINESCENCE SPECTROSCOPY:}

The photoluminescence spectra of the as prepared pure $\mathrm{ZnO}$ nanoparticles are excited at $325 \mathrm{~nm}$ and are shown in about $365 \mathrm{~nm}$, a stronger and broad violet emission peak at $540 \mathrm{~nm}$ for various concentrations are observed from analysis. In the case of $\mathrm{ZnO}$ nanoparticles, It is well reported figure 3.a. A rather broader near band edge emission peak at

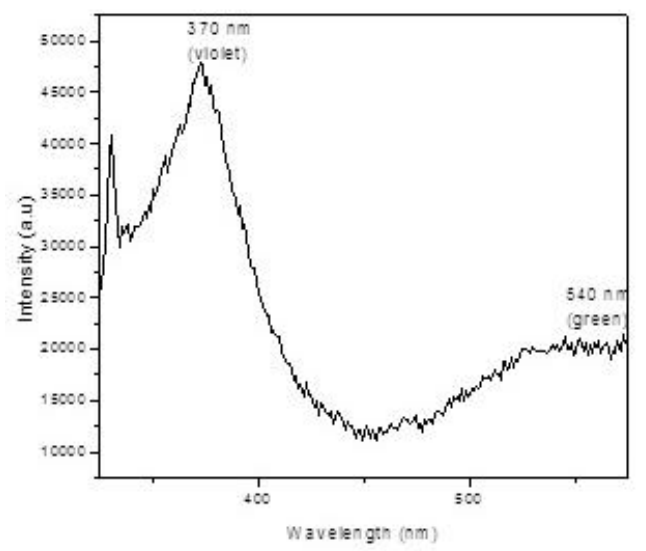

Figure3.a.UV-Visible spectrumof 1gm PVP+0.5gm ZnO

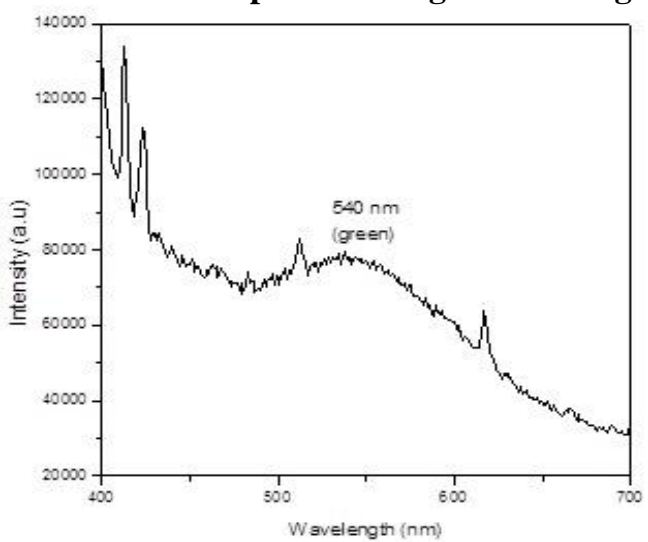

Figure 3.b. UV-Visible spectrumof 1gm PVP+1gm ZnO

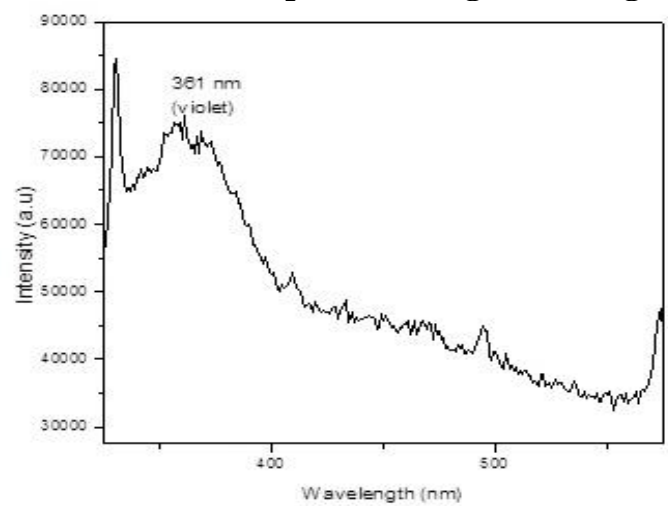

Figure 3.c. UV-Visible spectrum of $1 \mathrm{gm} P V P+1.5 \mathrm{gm} \mathrm{ZnO}$

and expected to receive a stronger deep level emission in the visible region as the function of the concentration. It is further referenced that bulk material show weak luminescence owing to their indirect band gap property. It is also believed that the quantum confinement is also reasoned for the band gap nature was changed from indirect to direct band gap. From the band to band transition, the calculated band gap from the energy - frequency relation $\mathrm{E}=\mathrm{hv}$ and its calculated value is $3.8 \mathrm{eV}$. When being direct band gap for pure material it shows wider photoluminescence was possible. From this result, it is observed that, the quantum confinement effect takes place [15]. The Illustrated figure (3.b and 3.c) shows the photo luminescence spectra of pure $\mathrm{ZnO}$ nanocomposites in the PVP matrix were excited at $425 \mathrm{~nm}$ and $330 \mathrm{~nm}$ and the emission peaks are obtained at $540 \mathrm{~nm}$ and $361 \mathrm{~nm}$. 
It shows near green region and maximum emission intensity were obtained around at $280 \mathrm{~nm}$ with very strong and violet emissions are obtained at $361 \mathrm{~nm}$. The direct band gap for pure $\mathrm{ZnO}$ is $3.5 \mathrm{ev}$.

\section{PL SPECTRUM OF SILVER DOPED ZNO NANOCOMPOSITES}

We investigated the emission behavior of the silver doped $\mathrm{ZnO}$ nanocomposite with different $\mathrm{AgNO} 3$ concentrations. The photoluminescence from the roughened surface of noble metals could be viewed as an excitation of electrons from occupied d-bands into states above the Fermi level and the similar mechanism is responsible for the nano cluster photo luminescence. Subsequent electron-phonon and hole-phonon scattering process lead to energy loss and finally photo luminescent recombination of an electron from an occupied sp band with the hole. On the other hand, there was no photoluminescence for large metal particles, for this rapid radiation less processes. It has been suggested that the fluorescence from monolayer-protected silver nanoparticles is caused by smaller cluster derived from the interaction between the surface of monolayer protected nanoparticles and the solvent under the exciting light.

Figure(3.d.) \&figure(3.e.) shows the photoluminescence spectrum of the silver doped $\mathrm{ZnO}(0.5 \mathrm{~g})$ excited at $300 \mathrm{~nm}$, the emission peaks are $375 \mathrm{~nm}$ and $440 \mathrm{~nm}$ for blue region and the silver doped $\mathrm{ZnO}(1.5 \mathrm{~g})$ excited at $440 \mathrm{~nm}$ and the emission peaks are $540 \mathrm{~nm}$ near green region. The direct band gap for doped material is $2.8 \mathrm{eV}$.

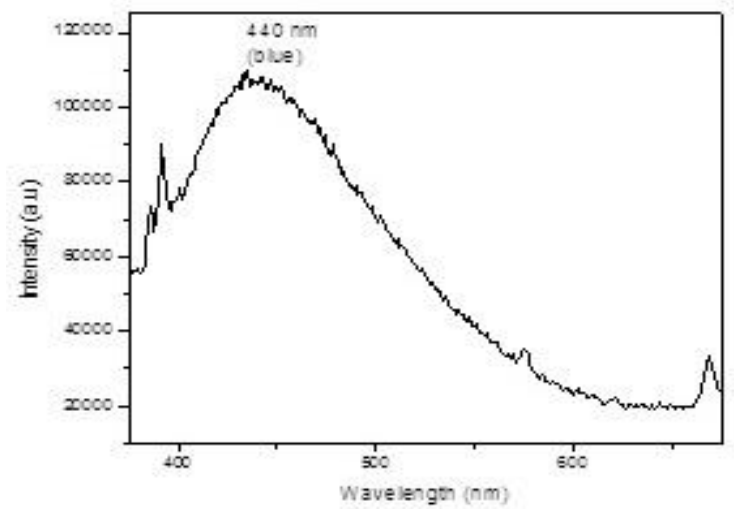

Figure 3.d. UV-Visible spectrumof 1 g PVP + 0.5 g ZnO +

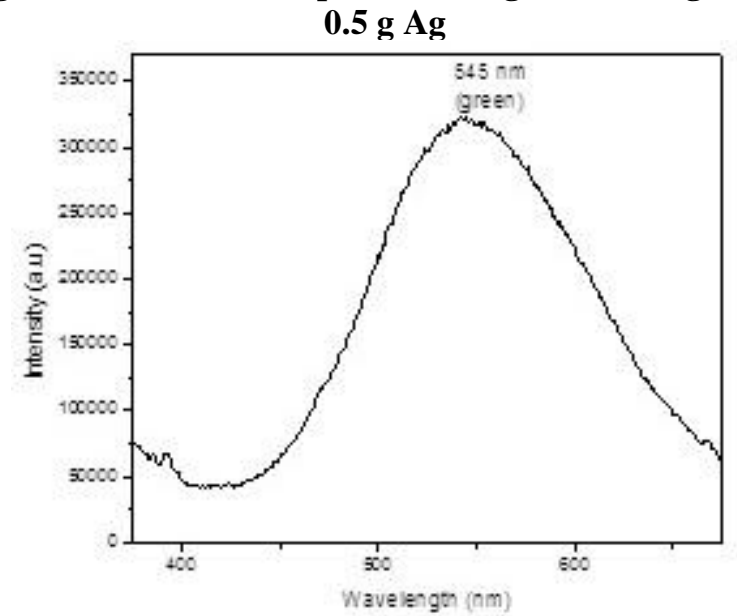

Figure 3.e. UV-Visible spectrum of $1 \mathrm{~g}$ PVP + $1.5 \mathrm{~g} \mathrm{ZnO} \mathrm{+}$ $1.5 \mathrm{~g} \mathrm{Ag}$

\section{FTIR SPECTROSCOPY:}

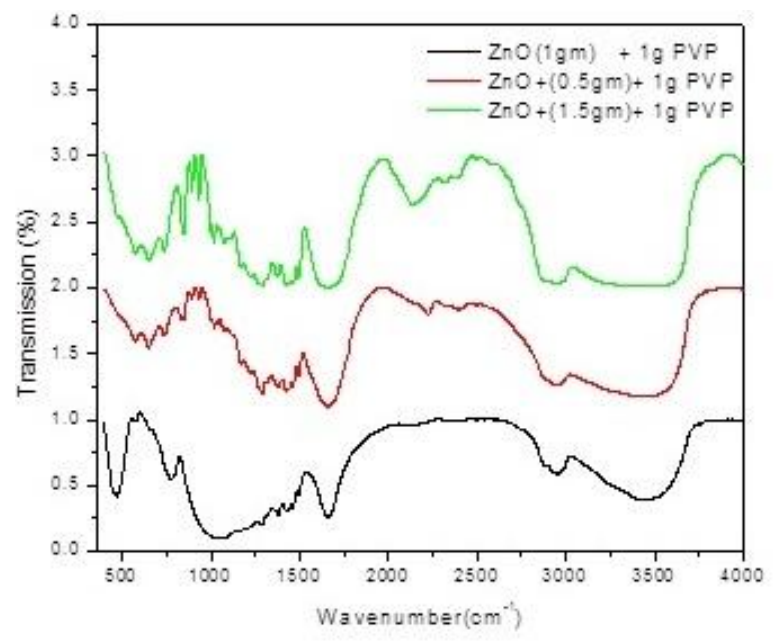

Figure 4.a. FT-IR spectrum of $\mathrm{ZnO}$ with PVP Nanoparticles

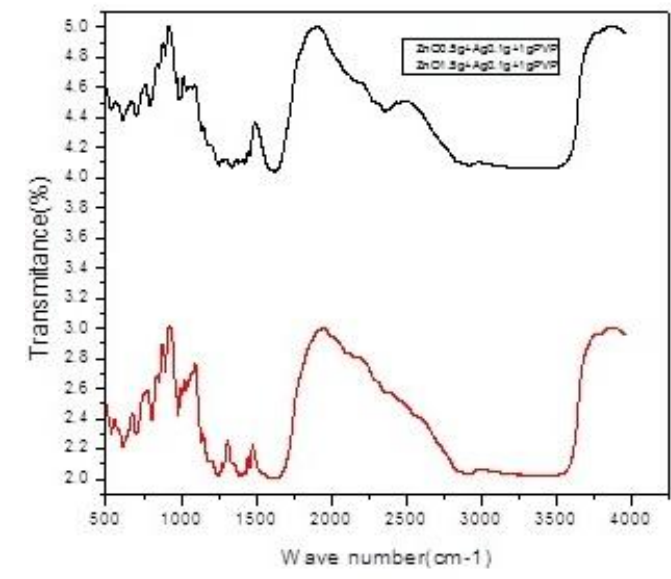

Figure 4.b. FT-IR spectrum of Silver doped $\mathrm{ZnO}$ nanocomposites

The natural vibration of atoms in molecules in the infrared ranges which facilities to identify the short range ordering of atoms in a material. Further this technique is to identify the reaction between the solids by monitoring the vibrational and rotational motion of molecules during the reaction. The KBR pellet technique was employed for recording the FTIR spectra using 84005 Shimadzu spectrometer (With the resolution of $3 \mathrm{~cm}-1$ in the wavelength range of 3000-3500 $\mathrm{cm}-1$ ). In fig (4.a.) shows that the broad peak in $\mathrm{ZnO}$ nanoparticles. The $\mathrm{OH}$ group present in the sample, the peak which is located at $2935 \mathrm{~cm}-1$ to $2927 \mathrm{~cm}-1$ are due to the symmetric and asymmetric $\mathrm{C}-\mathrm{H}$ bonds respectively. The $\mathrm{C}-\mathrm{H}$ bonds are present in mono acetate are intermediate products from $1423 \mathrm{~cm}-1$ to $1384 \mathrm{~cm}-1$ peaks are attributed to asymmetric and symmetric $\mathrm{C}=\mathrm{O}$ bonds vibrations respectively. C-N bonds vibrate at $1010 \mathrm{~cm}-1,1066.61 \mathrm{~cm}-1$ and $1234.41 \mathrm{~cm}-1$. The $\mathrm{OH}$ vibration become sharper and all the vibration moderated due to increase in $\mathrm{ZnO}$ concentration. The PVP shifted peak from $1662 \mathrm{~cm}-1-1649 \mathrm{~cm}-1$ due to the presence of metal oxide nanoparticle inside the PVP matrix. For various concentrations of metal oxide nanoparticles shows the presence of PVP in low concentration. 
The FTIR spectra of $\mathrm{Ag} / \mathrm{ZnO}$ nanocomposites are provided in fig (4.b.).The peaks at $1658 \mathrm{~cm}-1$ and $1610 \mathrm{~cm}-1$ are attributed to $\mathrm{O}-\mathrm{H}$ stretching and bending vibrations of water molecules respectively. The band at around $1448 \mathrm{~cm}-1$ was attributed to the vibration mode $\mathrm{Ag}$ bond with $\mathrm{O}$, after the addition of $\mathrm{Ag}$ on the surface of $\mathrm{ZnO}$ nanoparticle the band around $861 \mathrm{~cm}-1$ disappear and new band $1251.5 \mathrm{~cm}-1$ was formed. The distinct differences between the IR band of $\mathrm{Ag} / \mathrm{Zno}$ nanocomposites were absorbed between $530 \mathrm{~cm}-1$ and $805 \mathrm{~cm}-1$. The differences of changes indicate that peak addition of $\mathrm{Ag}$ affected $\mathrm{ZnO}$ nanocomposites. The broad peak at 1621 is sharped due to increase metal oxide nanoparticle which indicates the presece of PVP matrix. These results were good agreement in the previous report.

\section{SEM ANALYSIS:}

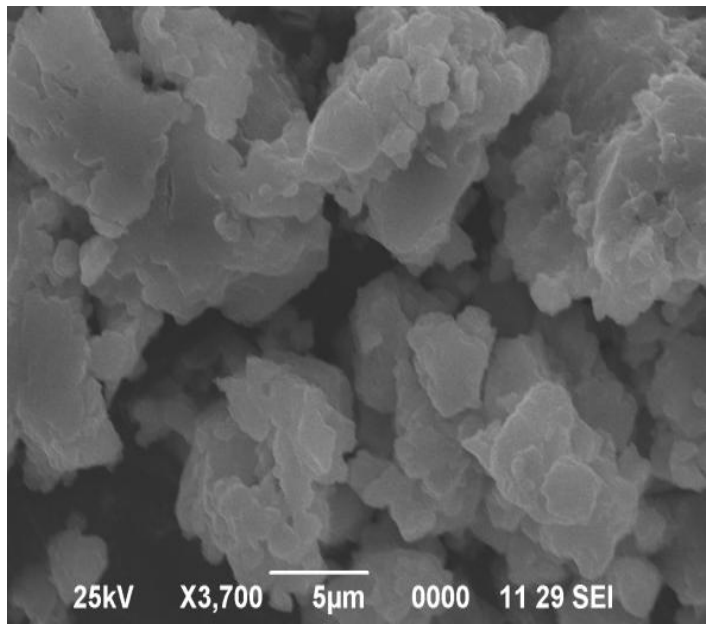

Figure.5.a. SEM image of $1 \mathrm{~g}$ PVP+1.5 g ZnO

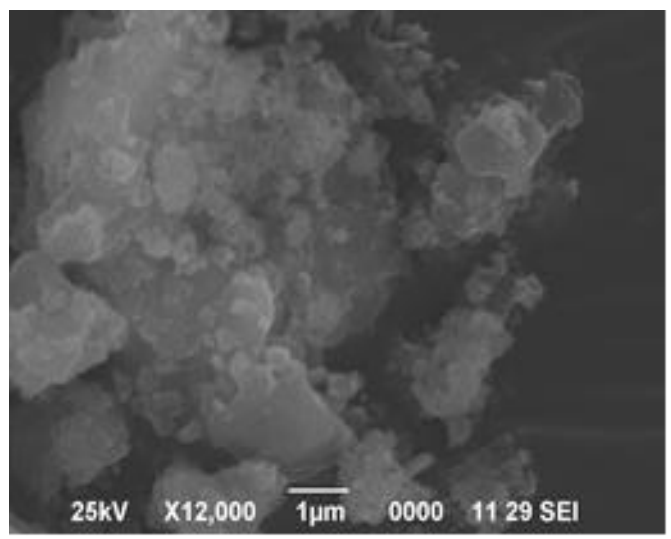

Figure 5.b. SEM image of $1.5 \mathrm{~g} \mathrm{ZnO}+0.1 \mathrm{~g} \mathrm{AgNO}_{3}+1 \mathrm{~g}$ PVP

The morphology analysis of prepared samples was done with scanning electron microscope. Figure (5.a.) shows the SEM images of the as prepared PVP encapsulated $\mathrm{ZnO}$ nanoparticles at $5 \mu \mathrm{m}$ magnifications. At low magnification, the formation of plate like structures has been clearly indicated.

Figure (5.b.) shows the SEM images of the PVP encapsulated silver doped $\mathrm{ZnO}$ nano composites. From low magnification image clearly view that the particle size and no structure had been clearly seen. The low magnification image was taken as in $1 \mu \mathrm{m}$ clearly shows the formations of the plates are piled up. The different morphologies were observed. Therefore its considered as a optimized sample for the further analysed.

\section{ANTIMICROBIAL ACTIVITY}

From the results it was concluded that the addition of silver doped $\mathrm{ZnO}$ nanocomposite into the microorganism damaged it in a lesser rate as compared with pure $\mathrm{ZnO}$ nanoparticles. Therefore, these results are helpful to confirm that the silver doped $\mathrm{ZnO}$ was very less toxic to living organisms but pure $\mathrm{ZnO}$ nanoparticles are suitable for killing effect of bacteria from environment i.e. for anti-microbial activity [16].

From the prepared nanoparticles, $0.5 \mathrm{gm}$ and $1.5 \mathrm{gm}$ of $\mathrm{ZnO}$ nanoparticle was taken and diluted in $10 \mathrm{ml}$ of ethanol and kept in ultrasonic agitator for $15 \mathrm{~min}$ to get fine dispersion of particles. The diluted $\mathrm{ZnO}$ nanoparticles solution was dropped into the grown bacteria and incubated After $12 \mathrm{hrs}$, the killing effect of human E.Coli bacteria was examined using fluorescence microscope and the same examination was repeated for after $24 \mathrm{hrs}$. The taken images (Fig 6.a. and 6.b.) were shown in in which the images corresponding to $12 \mathrm{hr}$ and $24 \mathrm{hrs}$ indicated the killing effect of bacteria after the addition of $\mathrm{ZnO}$ and starched capped $\mathrm{ZnO}$ nanoparticles $[17,18]$.

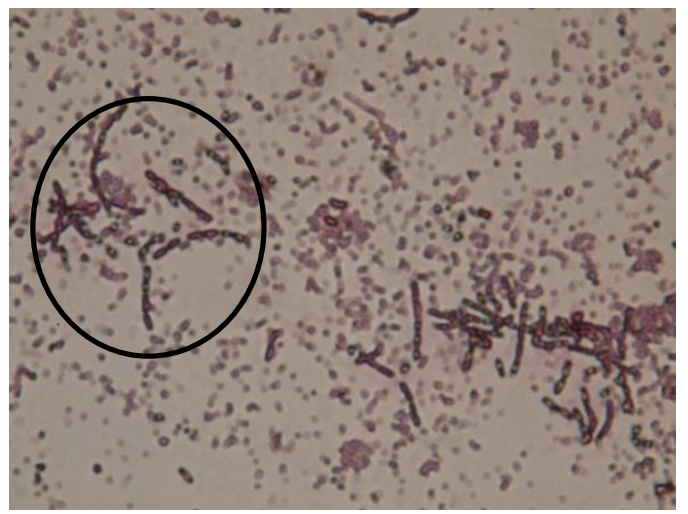

Figure. 6.a. Fluroscence image of $\mathrm{ZnO} 0.1 \mathrm{~g}+1 \mathrm{~g}$ PVP + $1 \mathrm{~g} \mathrm{Ag}$

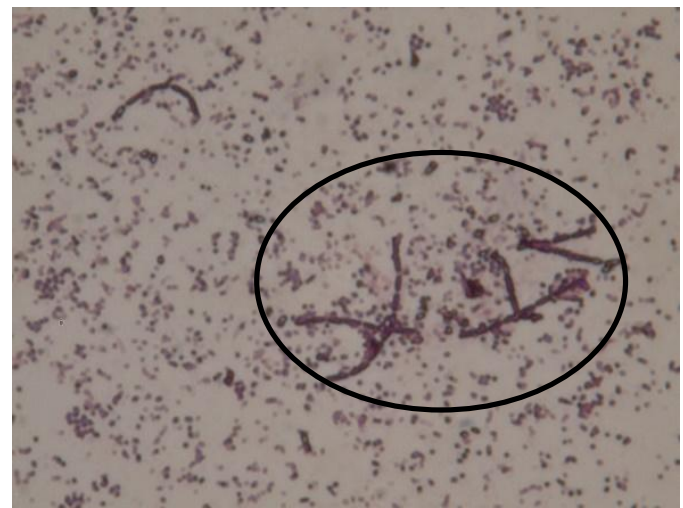

Figure. 6.b. Fluroscence image of $\mathrm{ZnO} 1.5 \mathrm{~g}+1 \mathrm{~g} \mathrm{PVP}+1$ g Ag 


\section{One Pot Synthesis and Spectral Analysis of Ag Doped Polyvinyl Pyrrolidone Encapsulated Zinc Oxide Nano Composites and its Antibacterial Efficacy}

\section{CONCLUSIONS}

The simple chemical method is employed for the preparation of the transition metal doped semiconducting materials. The synthesized nano material was preserved in an airtight container and it is subjected for various characterization tools like X -Ray Diffraction analysis, High Resolution Scanning Electron microscope Analysis, Photoluminescence studies, Ultra Violet Absorption and Fourier Transform Infrared Spectroscopic studies.

The XRD results reveal that the synthesized samples are in highly crystalline in state with nano dimensional state. The results also show that the sample does not contain any metal peak which shows that the synthesized samples are in highly pure phase. The HR SEM result shows that the materials are in Nano phase.

The UV visible absorption spectroscopic study shows strong absorption peaks of $\mathrm{ZnO}$ around $295 \mathrm{~nm}$ and $\mathrm{Ag}$ doped $\mathrm{ZnO}$ around $280 \mathrm{~nm}$ which is caused by the band edge transition of the synthesized semiconductor. The FT IR studies are also shows characteristic peaks for Pure $\mathrm{ZnO}$ and $\mathrm{Ag}$ doped $\mathrm{ZnO}$ nanocomposites. The functional groups peaks are also found in the spectrum and it is attributed as they are in the surface of the final product. The $\mathrm{ZnO}$ nano material behaves as a potential antimicrobial agent but the silver doped $\mathrm{ZnO}$ shows a lesser activity while comparing with the standard drug (Streptomycin).

\section{REFERENCES}

1. M. H. Habibi, R. Sheibani, J. Indust. Eng. Chem.,2013, 19, 161-165. b) X.Z. Meng, L. Xiaojing, H.R. Hang, X.H. Yueyue, W. Xiaohong, Y. B. Tang, X. Zhang, M. Li, X. He, R. Hang, X. Huang, Y.Wang, X. Yao, Appl. Sur. Sci., 2015, Article in press.

2. A.A. Aal, M.A. Barakat, R.M. Mohamed, Appl. Surf. Sci.,2008, 254, 4577. b) X. L. Cheng, H. Zhao, L. H. Huo, S. Gao, J. G. Zhao, Sens. Actuators B, 2004 102, 248

3. J.Y. Son, S.J. Lim, J.H. Cho, W.K. Seong, H. Kim, Appl. Phys. Lett., 2008, 93, 053109. b) Wnek G E, Carr M E, Simpson D G and Bowlin G L 2003 Nano Lett. 3213.

4. M.H. Cho, G.H. Lee, Thin Solid Films,2008, 516, 5877. b) M.Singhal, V. Chhabra, P. Kang, D. O. Shah, Material science Res. Bull., 32 (1997) 239-247.

5. M.R. Vaezi, J. Mater. Process. Technol., 205 (2008) 332. b) [4] H. Yang, Y. Ji Sun, W. Song, X. Zhu, Y. Yao, Z. Zhang, Corros. Sci. 50 (2008) 3160. c) M.H. Habibi, R. Sheibani, Bull. Environ. Contam. Toxicol. 2010, 85, 589. d) M. Montazerozohori, B. Karami, M.H. Habibi, Ann. Chim. 2006, 285, 5-6. e) M. Montazerozohori, B Karami, M.H. Habibi, Fresenius Environ. Bull., 2007, 1644.

6. N. Wang, X.Y. Li, Y.X. Wang, Y. Hou, X.J. Zou, G.H. Chen, Mater. Lett., 2008, 62, 3691. b) A. Hilonga, J.K. Kim, P.B. Sarawade, H.T. Kim, Applied Surface Science2009, 255, 8239. c) A. Hilonga, J.K. Kim, P.B. Sarawade, H.T. Kim, Applied Surface Science2010, 256 2849-2855. d) H. Liu, Q. Chen, L. Song, R. Ye, J. Lu, H. Li, Journal of Non-Crystalline Solids, 2008, 354 1314-1317. e) D.V. Quang, P.B. Sarawade, A. Hilonga, S.D. Park, J.K. Kim, H.T. Kim, Applied Surface Science, 2011, 257, 4250-4256.

7. L.X. Shi, H. Shen, L.Y. Jiang, X.Y. Li, Mater. Lett., 2007, 61, 4735. b) T. Toshikazu, Inorganic Materials,1999, 6, 505-511. c) M. Kawashita, S. Tsuneyama, F. Miyaji, T. Kokubo, H. Kozuka, K. Yamamoto, Biomaterials, 2000, 21, 393. d) L. Miao, P. Jin, K. Kaneko, A. Terai, N. Nabatova-Gabain, S. Tanemura, Applied Surface Science, 2003, 212, 255-263.

8. M.H. Habibi, M. Mikhak, Appl. Surf. Sci., 2012, 258, 6745. S.M. Hosseini, b) I. A. Sarsari, P. Kameli, H. Salamati, J. Alloys Compounds, 2015, 640, 408-415. c) A. Tsukazaki, A. Ohtomo, T. Onuma, M. Ohtani, T. Makino, M. Sumiya, K. Ohtani,

9. S.F. Chichibu, S. Fuke, Y. Segawa, Nat. Mater., 2004, 4, 42-46. d) U. Ozgur, Y.I. Alivov, C. Liu, A. Teke, M. Reshchikov, S. Dogan, V. Avrutin, S.J. Cho, H. Morkoc, J. Appl. Phys., 2005, 98, 041301. e) M. Ahmad, J. Zhao, J. Iqbal, W. Miao, L. Xie, R. Mo, J. Zhu, J. Phys. D: Appl. Phys., 2009, 42, 165406. f) S.T. Teklemichael, W.H. Oo, M
McCluskey, E.D. Walter, D.W. Hoyt, Appl. Phys. Lett., 2011, 98 , 232112.

10. D.V. Quang, P.B. Sarawade, A. Hilonga, S.D. Park, J.K. Kim, H.T Kim, Appl. Surf. Sci., 2011, 257, 4250-4256. b) [12] C. Karunakaran, V. Rajeswari, P. Gomathisankar, Solid State Sci., 2011, 13, 923-928. c) P. Amornpitoksuk, S. Suwanboon, S. Sangkanu, A. Sukhoom, N. Muensit, J. Baltrusaitis, Powd. Technol., 2012, 219, 158-164. d) T. Chen, Y. Zheng, J.-M. Lin, G. Chen, J. Am. Soc. Mass Spectro., 2008 $19,997-1003$

11. D. Gangadharan, K. Harshvardan, G. Gnanasekar, D. Dixit, K.M Popat, P.S. Anand, Water Research, 2010, 44 5481-5487. b) M Jelinek, T. Kocourek, J. Remsa, M. Weiserová, K. Jurek, J. Mikšovský, J. Strnad, A. Galandáková, J.Ulrichová, Materials Science and Engineering C, 2013, 33, 1242-1246,c) A.B.G. Lansdown, in: G. Burg (Ed.), Curr Probl. Dermatol, Basel, Karger, 2006. c) Y. Chen, X. Zheng, Y. Xie, Ch. Ding, H. Ruan, C. Fan, J. Mater. Sci. Mater. Med.,2008, 19, 3603-3609. d) W. Chen, Y. Liu, H.S. Courtney, M. Bettenga, C.M. Agrawal, J.D. Bumgardner, J.L. Ong, Biomaterials, 2006, 27, 5512-5517. e) R.J. Chung, M.F. Hsieh, K.C. Huang, L.H Perng, F.I. Chou, T.S. Chin, J. Sol-Gel Sci. Technol., 2005, 33, 229-239.

12. R. Bandyopadhyaya, M.V. Sivaiah, P.A. Shankar, J. Chem. Tech Biotech.,2008, 83 1177-1180. b) C.F. Koch, S. Johnson, D. Kumar, M Jelinek, D.B. Chrisey, A. Doraiswamy, C. Jin, R.J. Narayan, I.N Mihailescu, Mater. Sci. Eng. C, 2007, 27, 484-494. c) R.K. Appleyard, Genetics, 1954, 39, 440-452. c) M. Madigan, J. Martinko, (Eds.), Brock Biology of Microorganisms, 11th Ed.,

13. Prentice Hall, 2005. d) S.E. Luria, Cold Spring Harb. Symp. Quant Biol., 1953, 18, 237-244.

14. Y. Lv, H. Liu, Z. Wang, S. Liu, L. Hao, Y. Sang, D. Liu, J. Wang, R.I Boughton, J Memb. Sci.,2009, 331 50-56. b) K. SanthoshKumar A.GowriManohari, S.Dhanapandian, T.Mahalingam, Materials Letters (Article in press). b) A. Akkari, M. Reghima, G. Cathy, N.K. Turki, J Mater Sci., 2012, 47 1365-71. c) Y. Yang,S. Cheng, J Semicond.,2008,29, 2322-5. d) G. Manohari, D.S, Manoharan, K.Santhosh, T. Mahalingam, Mater. Sci. Semicond. Process,2014, 17 , 138-42. e) D.F. Paraguay, J. Morales,W. EstradaL, W. Andrade, M.M Yoshide. Thin Solid Films, 2000, 366, 16-27.

15. D. Rajkumar, K. Palanivelu, J. Hazard. Mater., 2004, 113, 123-129. b) H. Noguchi,A. Stiyadi,H. Tanamura,T. Nagatomo,O. Omoto. Sol. Energy. Mater. Sol. Cells,1994, 35, 325-31. c) M. Ichimura, K.Takeuchi,Y. Ono, E. Arai, Thin Solid Films, 2000, 361, 98-101. d) M.M.E. Nahass, H.M. Zeyada, M.S. Aziz,N.A. El-Ghamaz, Opt. Mater., 2002, 20, 159-70. e) N.K. Reddy, K. Ramesh,R Ganesan,K.T.R. Reddy, K.R. Gunasekhar, E.S.R. Gopal, Appl. Phys. A, 2006, 83,133-8

16. D.G. Thomas, J. Phys. Chem. Solids, 1960, 15, 86. b) J. Bardeen,F.J. Blatt.,L.H. Hall, Proceeding soft hephotoconductivity conference. Atlantic City, NewYork, Wiley, 1956;146. c) T. Minami,T Kakumu,Y. Takeda, S. Takata.Thin Solid Films,1996; 290,1-5. d) G.L. Rusu, M.E. Popa, G.G. Rusu, Appl. Surf. Sci., 2003, 218, 223-31

17. E. Tang, G. Cheng, X. Ma, Powder Technology, 2006, 161, 209-214 b) A. Peetscha, C. Greulich, D. Braun, C. Stroetges, H. Rehaged, B. Siebers, M. Koller, M. Epple,Colloids and Surfaces B Biointerfaces,2013, 102, 724- 729. c) A.I. Hidron, J.R. Edwards, J. Patel, T.C. Horan, D.M. Sievert, D.A. Pollock, S.K. Fridkin, Infect. Control Hosp. Epidemiol., 2008, 29, 996-1011. c) S.R. Harris, E.J. Feil, M.G. Holden, M.A. Quail, E.K. Nickerson, N. Chantratita, S. Gardete, A. Tavares, N. Day, J.A. Lindsay, J.D. Edgeworth, H. de Lencastre, J. Parkhill, S.J. Peacock, S.D. Bentley, Science, 2010, 327 469-474. d) C.G. Giske, D.L. Monnet, O. Cars, Y. Carmeli, Antimicrob. Agents Chemother., 2008, 52, 813-821. e) M.A. Fischbach, C.T. Walsh, Science 325 (2009) 1089-1093.

18. G. Carotenuto, G. P. Pepe and L. Nicolais. Eur. Phys. J. B, 2007, 16 11-17. b) R.K. Tamrakar, I.P. Sahu, C.S. Robinson, D.P. Bisen, K Uplop, Journal of Taibah University for Science.,2015 (Article in Press)

19. A.I. Vogel. "Text book of Practical Organic Chemistry", 5th edn Longmann London1989, 264.

20. S. Arunachalam, N. Padma Priya, C. Saravanakumar, C. Jayabalakrishnan, V. Chinnusamy, J. Coord. Chem., 2010, 63. 1795-1806. b) S. Arunachalam, N. Padma Priya, K. Boopathi, C. Jayabalakrishnan, V. Chinnusamy, Appl. Organomet. Chem., 2010, 24, 491-498. 


\section{AUTHORS PROFILE}

Dr. S. Arunachalam is Assistant Professor in Department of Chemistry, International Research Centre, Kalasalingam Academy of Research and Education (Deemed to be University), Krishnankoil, India. His area of Research is Inorganic and Bio-inorganic chemistry, Photocatalysis, etc.

M. Arunpandian is a research scholar at Nanomaterial Laboratory, Department of Chemistry, International Research Centre, Kalasalingam Academy of Research and Education (Deemed to be University), Krishnankoil, India. He is working in the area materials Characterization, waste water purification and Photocatalysis. 